\title{
Updated Mortality Analysis of Radiation Workers at Rocketdyne (Atomics International), 1948-2008
}

\author{
John D. Boice, Jr., ${ }^{a, b, 1}$ Sarah S. Cohen, ${ }^{a}$ Michael T. Mumma, ${ }^{a}$ Elizabeth Dupree Ellis, ${ }^{c}$ Keith F. Eckerman, ${ }^{d}$ \\ Richard W. Leggett, ${ }^{d}$ Bruce B. Boecker, ${ }^{e}$ A. Bertrand Brill ${ }^{b}$ and Brian E. Henderson ${ }^{f}$ \\ ${ }^{a}$ International Epidemiology Institute, Rockville, Maryland 20850; ${ }^{b}$ Vanderbilt University Medical School and Vanderbilt-Ingram Cancer Center, \\ Nashville, Tennessee; " Oak Ridge Associated Universities, Oak Ridge, Tennessee; ' Oak Ridge National Laboratory, Oak Ridge, Tennessee; \\ e Lovelace Respiratory Research Institute, Albuquerque, New Mexico; and f University of Southern California, Los Angeles, California
}

Boice, J. D., Jr., Cohen, S. S., Mumma, M. T., Ellis, E. D., Eckerman, K. F., Leggett, R. W., Boecker, B. B., Brill, A. B. and Henderson, B. E. Updated Mortality Analysis of Radiation Workers at Rocketdyne (Atomics International), 1948-2008. Radiat. Res. 176, 244-258 (2011).

Updated analyses of mortality data are presented on 46,970 workers employed 1948-1999 at Rocketdyne (Atomics International). Overall, 5,801 workers were involved in radiation activities, including 2,232 who were monitored for intakes of radionuclides, and 41,169 workers were engaged in rocket testing or other non-radiation activities. The worker population is unique in that lifetime occupational doses from all places of employment were sought, updated and incorporated into the analyses. Further, radiation doses from intakes of 14 different radionuclides were calculated for 16 organs or tissues using biokinetic models of the International Commission on Radiation Protection (ICRP). Because only negligible exposures were received by the 247 workers monitored for radiation activities after 1999, the mean dose from external radiation remained essentially the same at $13.5 \mathrm{mSv}$ (maximum $1 \mathrm{~Sv}$ ) as reported previously, as did the mean lung dose from external and internal radiation combined at $19.0 \mathrm{mSv}$ (maximum 3.6 Sv). An additional 9 years of follow-up, from December 31,1999 through 2008, increased the person-years of observation for the radiation workers by $21.7 \%$ to 196,674 (mean 33.9 years) and the number of cancer deaths by $50 \%$ to 684. Analyses included external comparisons with the general population and the computation of standardized mortality ratios (SMRs) and internal comparisons using proportional hazards models and the computation of relative risks (RRs). A low SMR for all causes of death (SMR 0.82; 95\% CI $0.78-0.85$ ) continued to indicate that the Rocketdyne radiation workers were healthier than the general population and were less likely to die. The SMRs for all cancers taken together (SMR 0.88; 95\% CI 0.81-0.95), lung cancer (SMR 0.87; 95\% CI 0.76-1.00) and leukemia other than chronic lymphocytic leukemia (CLL) (SMR 1.04; 95\% 0.67-1.53) were not significantly elevated. Cox regression analyses revealed no significant dose-response trends for any cancer. For all cancers

${ }^{1}$ Address for correspondence: International Epidemiology Institute, 1455 Research Blvd., Suite 550, Rockville, MD 20850. e-mail: john.boice@vanderbilt.edu. excluding leukemia, the $\mathrm{RR}$ at $100 \mathrm{mSv}$ was estimated as 0.98 (95\% CI 0.82-1.17), and for all leukemia other than CLL it was $1.06(95 \%$ CI $0.50-2.23)$. Uranium was the primary radionuclide contributing to internal exposures, but no significant increases in lung and kidney disease were seen. The extended follow-up reinforces the findings in the previous study in failing to observe a detectable increase in cancer deaths associated with radiation, but strong conclusions still cannot be drawn because of small numbers and relatively low career doses. Larger combined studies of early workers in the United States using similar methodologies are warranted to refine and clarify radiation risks after protracted exposures. (c) 2011 by Radiation Research Society

\section{INTRODUCTION}

Rocketdyne (Atomics International) facilities in California include the Santa Susana Field Laboratory (SSFL) and the Canoga Park and De Soto sites. Atomics International merged with Rocketdyne, a rocket engine test facility, in the 1950s. Ten research nuclear reactors (nine operated at power levels below $1 \mathrm{MW}$ ) and seven criticality facilities operated over the years. Other radiation-related activities included fabricating nuclear fuel, disassembling and decontaminating reactor facilities, decladding spent nuclear fuel and storing nuclear material. During the years 1958 through 1983, enriched uranium and plutonium fuels were fabricated for research, space and power reactors.

Activities at the Santa Susana Field Laboratory, situated in the Simi Valley, included a sodium reactor experiment that produced electricity for the city of Moorpark for a short time in 1957. This first commercial use of a nuclear power reactor generated much public interest, including coverage on Edward R. Murrow's television show, "See It Now." Later, however, it was the site of one of the first reactor accidents with the core melting in 1959. After cleanup activities were completed and repairs made, the reactor operated for several more years.

Results of analyses of mortality data on 5,801 radiation workers and 41,169 non-radiation workers 


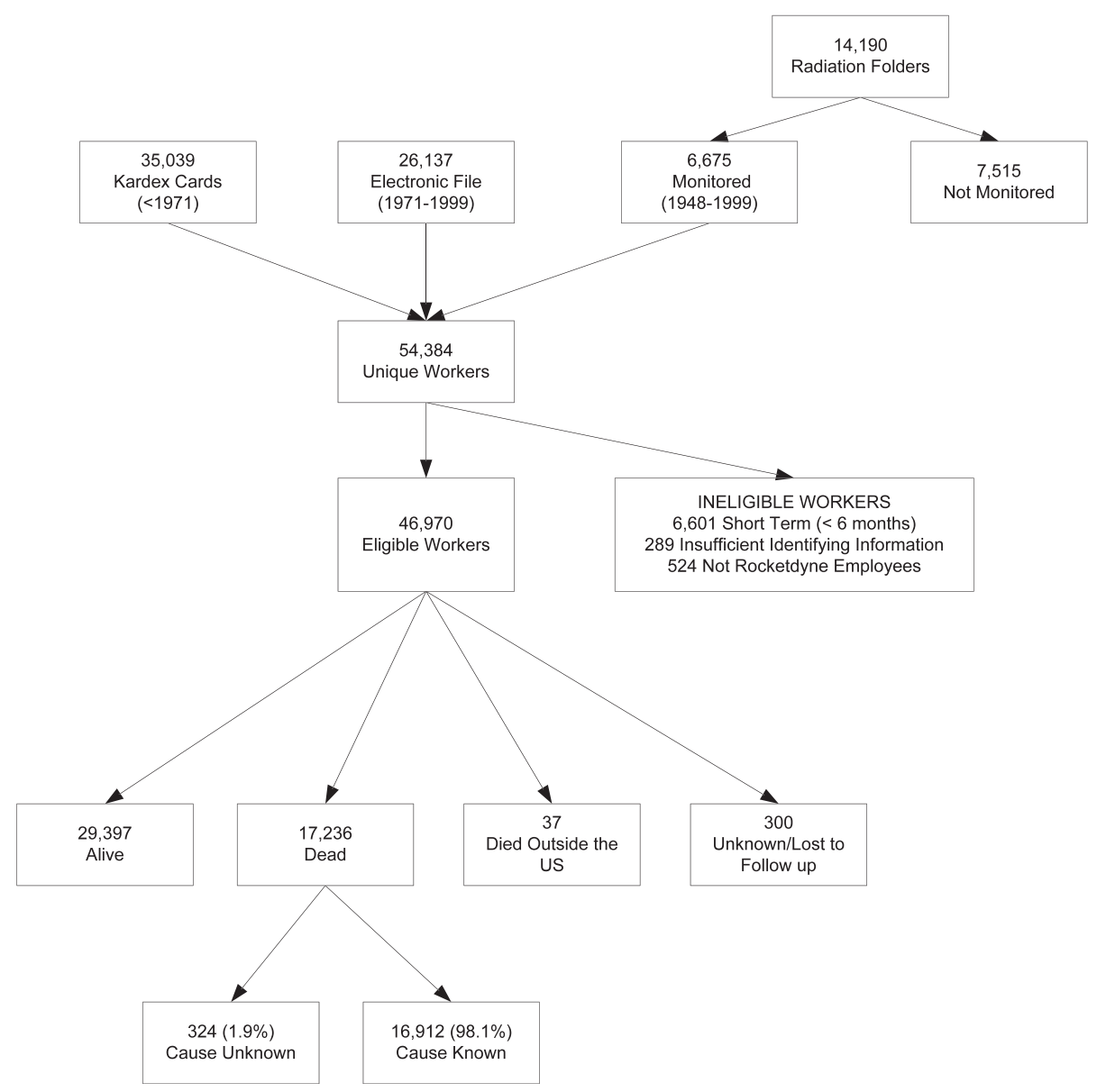

FIG. 1. Vital status of eligible Rocketdyne workers.

employed at Rocketdyne during 1948-1999 were reported in 2006 (1). A comprehensive dose reconstruction program incorporated lifetime occupational doses received at all known places of employment into the analyses as well as internal doses from radionuclide intakes $(2,3)$. No statistically significant elevations in cancer rates were observed after a mean follow-up of 27.9 years. For all cancers excluding leukemia, the RR at $100 \mathrm{mSv}$ was estimated as 1.00 (95\% CI $0.81-1.24)$, and for all leukemia other than chronic lymphocytic leukemia (CLL) it was 1.34 (95\% CI 0.73-2.45). An extended follow-up was conducted through 2008 (the last year for which cause of death was available from the National Death Index), adding another 9 years of observation (updated mean, 33.9 years) during the ages later in life when cancer rates are increasing.

\section{METHODS}

Human subjects research approval for the extended study was received from Vanderbilt University.

\section{Cohort Definition}

The study cohort has been described previously (1). In brief, 46,970 eligible workers were identified from work history cards, electronic files and radiation folders (Fig. 1). A total of 5,801 radiation workers employed on or after January 1, 1948 for at least 6 months were identified from the Rocketdyne California facilities at the Santa Susana Field Laboratory or nearby facilities at Canoga Park and De Soto. For comparison, 41,169 workers were identified who were employed at least 6 months at these same facilities and who were not monitored for radiation. Most workers employed by Rocketdyne over the years were not involved in radiation activities but rather in the testing and development of rocket engines, including the Saturn rocket engine used for the Apollo moon landings and the Redstone rocket engine that launched the first U.S. satellite, Explorer. These non-monitored workers did not come in contact with radiation sources and were not monitored for radiation.

\section{Vital Status Determination}

Updated mortality and vital status as of December 31, 2008 for the radiation workers were determined from various linkages of the study roster with national databases including the National Death Index (NDI), the California Death Statistical Master File, the Social Security Administration (SSA) Death Master File, other SSA files for alive status, Comserv, a computer services firm specializing in locating persons (www.comserv-inc.com), and LexisNexis, an online information service provider (www.lexisnexis.com). For matching with the SSA Death Master File and the California Death Statistical Master File, we used the Centers for Disease Control and Prevention matching program, LinkPlus, which incorporates a probabilistic scoring system and does not require exact matches on all variables (4). All probabilistic matches were then reviewed individually before a decision on the validity of the match was made. Among radiation 
TABLE 1

Characteristics of Rocketdyne Workers Who Were Monitored for External and/or Internal Radiation and Nonmonitored Workers, Followed 1948-2008

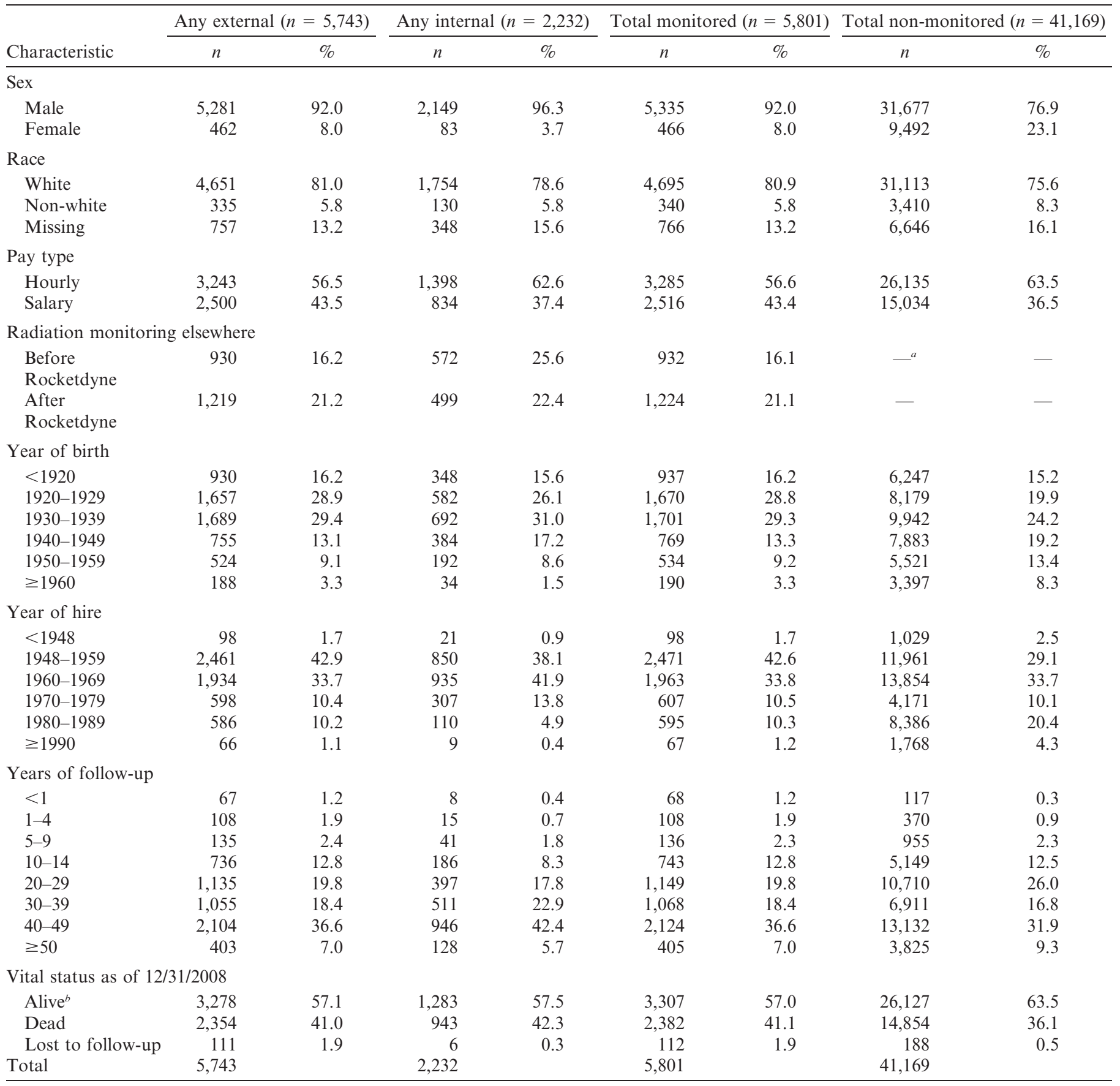

a $3.6 \%$ of the non-radiation workers had been monitored elsewhere.

${ }^{b}$ The 37 workers who died outside the U.S. were counted as alive until the last date they were known to reside in the U.S.

workers, SSA files and other sources confirmed that 3,307 workers $(57.0 \%)$ were alive in 2008 (Table 1). An additional 914 deaths $(38.4 \%$ of the updated total of 2,382) were identified, and cause of death was determined for all but $36(1.5 \%)$. There were $112(1.9 \%)$ workers without an SSA, California mortality or NDI match who were assumed alive up until their date of last employment at Rocketdyne. Comparable tracing results were found for the non-radiation workers, although there were fewer deaths proportionally in this younger cohort.
Dose Reconstruction

A comprehensive approach to estimating doses received by Rocketdyne employees has been described (5). Briefly, lifetime occupational doses from all places of employment were sought, and radiation doses from intakes of 14 different radionuclides were calculated for 16 organs or tissues using current biokinetic models of the International Commission on Radiation Protection (ICRP) or 
updated versions of those models proposed for use in upcoming ICRP documents $(2,5,6)$. The radionuclides with documented intakes included isotopes of uranium, plutonium, americium, calcium, cesium, cerium, zirconium, thorium, polonium, promethium, iodine, zinc, strontium and hydrogen (tritium). Over 30,000 individual bioassay measurements were abstracted. For workers with intakes of uranium aluminide, the ICRP respiratory model was modified to account for delayed dissolution of inhaled material in the respiratory tract (2). The most recent biokinetic models for polonium were also applied $(5,7)$. Overall, the most significant contribution to the estimated doses from internally deposited radionuclides came from enriched uranium. The highest estimated doses to lung and kidney came from intake of uranium, to bone surface from intake of plutonium, strontium or thorium, and to liver and testes from intake of plutonium.

Annual radiation doses received before and after employment at Rocketdyne had been obtained from the Department of Energy, the Nuclear Regulatory Commission, Landauer, Inc., and U.S. military services. The mean dose from external radiation was $13.5 \mathrm{mSv}$ (maximum $1 \mathrm{~Sv}$ ), and the mean lung dose from external and internal radiation combined was $19.0 \mathrm{mSv}$ (maximum 3.6 Sv). All workers known to be alive at last follow-up were again linked to the dosimetry systems of Landauer, Inc., the DOE REMS database and the NRC REIRS database to determine any occupational radiation doses received after 1999 through 2008. Updated organ doses from internally deposited radionuclides were also estimated through 2008 for those known to be alive on December 31, 2008 or until the time of death for those who died earlier.

\section{Analytic Methods}

Both external and internal analyses were carried out to estimate the relative risks (RR) of death from cancer and other diseases. Standardized mortality ratio (SMR) analyses compared the numbers of deaths observed among cohort members with the numbers expected based on general population rates in the state of California for persons of the same age, race and sex over the same periods (8). Internal analyses applied Cox proportional hazards models comparing radiation workers with non-monitored workers over categories of estimated radiation dose to specific organs (9). All of the analyses were based on the underlying cause of death as coded from the death certificate. This is standard practice in epidemiological studies because underlying causes of death are thought to be recorded in a more systematic fashion across time by physicians than "contributing" causes. For the $13 \%$ of workers with unknown race, a weighted approximation based on the proportions of race for the $87 \%$ of workers with known race was used to compute expected numbers.

Person-years of follow up began 6 months after the date of first radiation monitoring (or 6 months after the date of first hire for nonradiation workers) or July 1, 1948, depending on which came later. Ninety-eight of the radiation workers and 1,035 of the non-monitored workers had been hired prior to 1948 when SSFL began operations; their person-years of follow-up for all analyses began on July 1, 1948. Person-years stopped at the date of death, December 31, 2008, age 95 or date lost to follow-up, whichever came first. In most analyses exposures were lagged 10 years for solid cancers and 2 years for leukemia; i.e., exposures occurring in these intervals prior to end of follow-up were excluded because they would be unlikely to contribute to the risk of cancer or leukemia mortality. Observed and expected numbers of deaths were also distributed over categories of external radiation dose and trend analyses were conducted following the methods of Breslow and colleagues (10).

Internal comparisons are expected to minimize biases that might exist when external comparisons with a general population are made. Internal comparisons compare radiation workers with non-radiation workers employed at the same facilities during the same calendar years. Year of birth, year of hire, sex, pay type (hourly/salary), duration of employment and work as a test stand mechanic were included in all models (SAS/STAT software, Version 9.2 of the SAS System for Windows, SAS Institute Inc., Cary, NC). Age at observation was used as the time variable for the hazard function in these internal analyses. Pay type was taken as an indicator of socioeconomic status and as a surrogate for lifestyle factors such as tobacco use $(1,11)$. Because of their hands-on experience with large quantities of engine fuels, oxidizers and solvents, rocket test stand mechanics were considered a unique group with highest potential exposure to toxic substances (12).

For the internal analyses, radiation workers entered the risk set at their first date of radiation monitoring at Rocketdyne plus 6 months. Workers not monitored for radiation entered the risk set at their first date of hire at Rocketdyne plus 6 months. Radiation exposure category was treated as a time-dependent covariate, allowing workers to be assigned to increasingly higher dose categories over time as their individual radiation doses accrued. Parameter estimates and standard errors for the exposure categories in the Cox models were used to obtain risk (or hazard) ratios and confidence intervals for death due to the cause under investigation compared to those in the referent group. Trend tests treated the radiation dose as a single, timedependent continuous measure, and one-sided $P$ values are presented unless otherwise stated. The direction of any trend, whether positive or negative, is also presented. Relative risks at $100 \mathrm{mSv}$ were computed for all cancers excluding leukemia, all leukemia other than chronic lymphocytic leukemia (CLL), and lung cancer.

The large group of workers not monitored for radiation was taken as the referent category and provided statistical stability in the risk estimates and trend evaluations. The all cancer (excluding leukemia) internal analyses were over categories of external dose, whereas the categories for the other cancers incorporated both external and internal radiation doses to specific organs (3). The data for all cancer (excluding leukemia) are presented over categories of external dose because, other than for lung dose and bone marrow dose, the contribution of internal radiation dose to organs or tissues was not appreciable. Because of small numbers, high-dose categories had to be combined for model convergence for most sites. The number of workers starting each dose interval and the associated person-years varied somewhat for each cause of death category because of the differing contributions of internal radiation dose to different organs. Diseases of a priori interest - based on possible associations seen in other studies and on knowledge of the likely distribution of uranium and other radionuclides within the body once inhaled or ingestedincluded lung disease/cancer, kidney disease/cancer, liver disease/ cancer, bone cancer, esophageal cancer and leukemia. No analyses were conducted using effective dose - a unit used in radiation protection that, while generally related to future risk, is not appropriate for retrospective epidemiological evaluation of radiation risks to specific organs or tissue (13).

\section{RESULTS}

Most of the Rocketdyne radiation workers were male (92.0\%), white (80.9\%), born before 1940 (74.3\%), hired before $1970(78.1 \%)$, followed for more than 30 years (62.0\%), and alive in 2008 (57.0\%) (Table 1). Overall, 3,569 workers were monitored only for external radiation, 2,174 workers for both external and internal radiation, and 58 workers only for internal radiation. There were 1,833 (nearly 32\%) radiation workers who were also monitored for radiation either before or after employment at Rocketdyne; 323 (5.6\%) workers had been monitored both before and after. Among the 2,232 $(38.5 \%)$ workers monitored for internal radiation, most $(1,940$ or $86.9 \%)$ had negligible intakes; i.e., bioassay 
TABLE 2

Observed and Expected $^{a}$ Numbers of Deaths and Standardized Mortality Ratios (SMRs) for Rocketdyne Workers Monitored for External and for Internal Radiation

\begin{tabular}{|c|c|c|c|c|}
\hline \multirow[b]{2}{*}{ Cause of death (ICD9) } & \multicolumn{4}{|c|}{ Any external radiation } \\
\hline & $\begin{array}{c}5,743 \\
194,731 \\
\text { Obs }\end{array}$ & Exp & $\mathrm{SMR}^{b}$ & $95 \% \mathrm{CI}$ \\
\hline All Causes of Death (001-999) & 2354 & 2895.3 & $0.81 *$ & $0.78-0.85$ \\
\hline All Malignant Neoplasms (140-208) & 672 & 772.6 & $0.88 *$ & $0.81-0.94$ \\
\hline Buccal Cavity \& Pharynx (140-149) & 10 & 17.6 & 0.57 & $0.27-1.04$ \\
\hline Esophagus (150) & 20 & 22.4 & 0.89 & $0.55-1.38$ \\
\hline Stomach (151) & 26 & 25.6 & 1.02 & $0.66-1.49$ \\
\hline Colorectal (153-154) & 68 & 75.3 & 0.90 & $0.70-1.15$ \\
\hline Colon $(153)$ & 58 & 60.9 & 0.95 & $0.72-1.23$ \\
\hline Rectum (154) & 10 & 13.3 & 0.75 & $0.36-1.38$ \\
\hline Biliary Passages \& Liver (155-156) & 12 & 24.0 & $0.51 *$ & $0.26-0.87$ \\
\hline Pancreas (157) & 35 & 41.7 & 0.84 & $0.59-1.17$ \\
\hline Larynx (161) & 10 & 7.9 & 1.27 & $0.61-2.34$ \\
\hline Bronchus, Trachea, \& Lung (162) & 209 & 244.0 & $0.86^{*}$ & $0.74-0.98$ \\
\hline Bone $(170)$ & 0 & 1.5 & 0.00 & $0.00-2.51$ \\
\hline Connective \& Other Soft Tissue (171) & 4 & 4.4 & 0.90 & $0.25-2.31$ \\
\hline Melanoma of Skin (172) & 12 & 14.3 & 0.84 & $0.43-1.46$ \\
\hline Breast $(174-175)$ & 8 & 8.2 & 0.97 & $0.42-1.91$ \\
\hline All Uterine (Females only) (179-182) & 2 & 1.8 & 1.10 & $0.13-3.98$ \\
\hline Cervix Uteri (180) & 0 & 0.8 & 0.00 & $0.00-4.48$ \\
\hline Ovary \& Other Female Genital Organs (183-184) & 1 & 2.7 & 0.38 & $0.01-2.09$ \\
\hline Prostate (Males only) (185) & 63 & 71.1 & 0.89 & $0.68-1.13$ \\
\hline Testes \& Other Male Genital Organs (186-187) & 1 & 1.8 & 0.56 & $0.01-3.12$ \\
\hline Kidney (189.0-189.2) & 17 & 19.5 & 0.87 & $0.51-1.40$ \\
\hline Bladder \& Other Urinary (188, 189.3-189.9) & 22 & 22.1 & 1.00 & $0.62-1.51$ \\
\hline Brain \& Central Nervous System (191-192) & 23 & 20.5 & 1.12 & $0.71-1.68$ \\
\hline Thyroid \& Other Endocrine Glands (193-194) & 1 & 2.4 & 0.42 & $0.01-2.32$ \\
\hline All Lymphatic Tissue (200-203) & 46 & 47.6 & 0.97 & $0.71-1.29$ \\
\hline Hodgkin Lymphoma (201) & 5 & 3.0 & 1.64 & $0.53-3.83$ \\
\hline Non-Hodgkin Lymphoma $(200,202)$ & 31 & 30.6 & 1.01 & $0.69-1.44$ \\
\hline Multiple Myeloma (203) & 10 & 14.0 & 0.71 & $0.34-1.31$ \\
\hline All Leukemia \& Aleukemia (204-208) & 33 & 29.8 & 1.11 & $0.76-1.56$ \\
\hline Chronic Lymphocytic Leukemia (204.1) & 8 & 5.9 & 1.36 & $0.59-2.68$ \\
\hline Leukemia other than CLL & 25 & 23.9 & 1.05 & $0.68-1.54$ \\
\hline Mesothelioma, MN of pleura \& peritoneum $(158.8,158.9,163)^{c}$ & 2 & 3.2 & 0.63 & $0.08-2.29$ \\
\hline Smoking-Related Cancers (140-150, 157, 161-162, 188-189) & 323 & 375.1 & $0.86^{*}$ & $0.77-0.96$ \\
\hline AIDS $(042-044,795.8)$ & 1 & 20.0 & $0.05^{*}$ & $0.00-0.28$ \\
\hline Diabetes $(250)$ & 30 & 64.6 & $0.46^{*}$ & $0.31-0.66$ \\
\hline Mental \& Behavioral Disorders (290-319) & 42 & 33.3 & 1.26 & $0.91-1.70$ \\
\hline Diseases of Nervous System \& Sense Organs (320-389) & 70 & 74.2 & 0.94 & $0.74-1.19$ \\
\hline Cerebrovascular Disease $(430-438)$ & 117 & 162.6 & $0.72 *$ & $0.60-0.86$ \\
\hline All Heart Disease (390-398, 404, 410-429) & 780 & 965.4 & $0.81 *$ & $0.75-0.87$ \\
\hline Nonmalignant Respiratory Disease $(460-478,490-519)^{d}$ & 148 & 185.0 & $0.80^{*}$ & $0.68-0.94$ \\
\hline Emphysema (492) & 30 & 31.2 & 0.96 & $0.65-1.37$ \\
\hline Cirrhosis of Liver (571) & 49 & 85.6 & $0.57 *$ & $0.42-0.76$ \\
\hline Nephritis \& Nephrosis (580-589) & 24 & 21.7 & 1.11 & $0.71-1.64$ \\
\hline All External Causes of Death (800-999) & 140 & 193.9 & $0.72 *$ & $0.61-0.85$ \\
\hline Accidents (850-949) & 80 & 114.5 & $0.70^{*}$ & $0.55-0.87$ \\
\hline Suicides (950-959) & 41 & 55.6 & 0.74 & $0.53-1.00$ \\
\hline Unknown Causes of Death & 36 & & - & - \\
\hline
\end{tabular}

${ }^{a}$ Expected number of deaths is based on California population mortality rates.

${ }^{b}$ All but 58 workers monitored for internal uptake of radionuclides were also monitored for external radiation.

${ }^{c}$ Mesothelioma was not a codeable cause of death until 1999: ICD10 (C45). Before 1999, deaths from cancer of the pleura and peritoneum (ICD9 $158.8,158.9,163$ ) are used to approximate mesothelioma mortality.

${ }^{d}$ Excludes flu and pneumonia.

$* P<0.05$. 
MORTALITY AMONG ROCKETDYNE WORKERS

TABLE 2

Extended

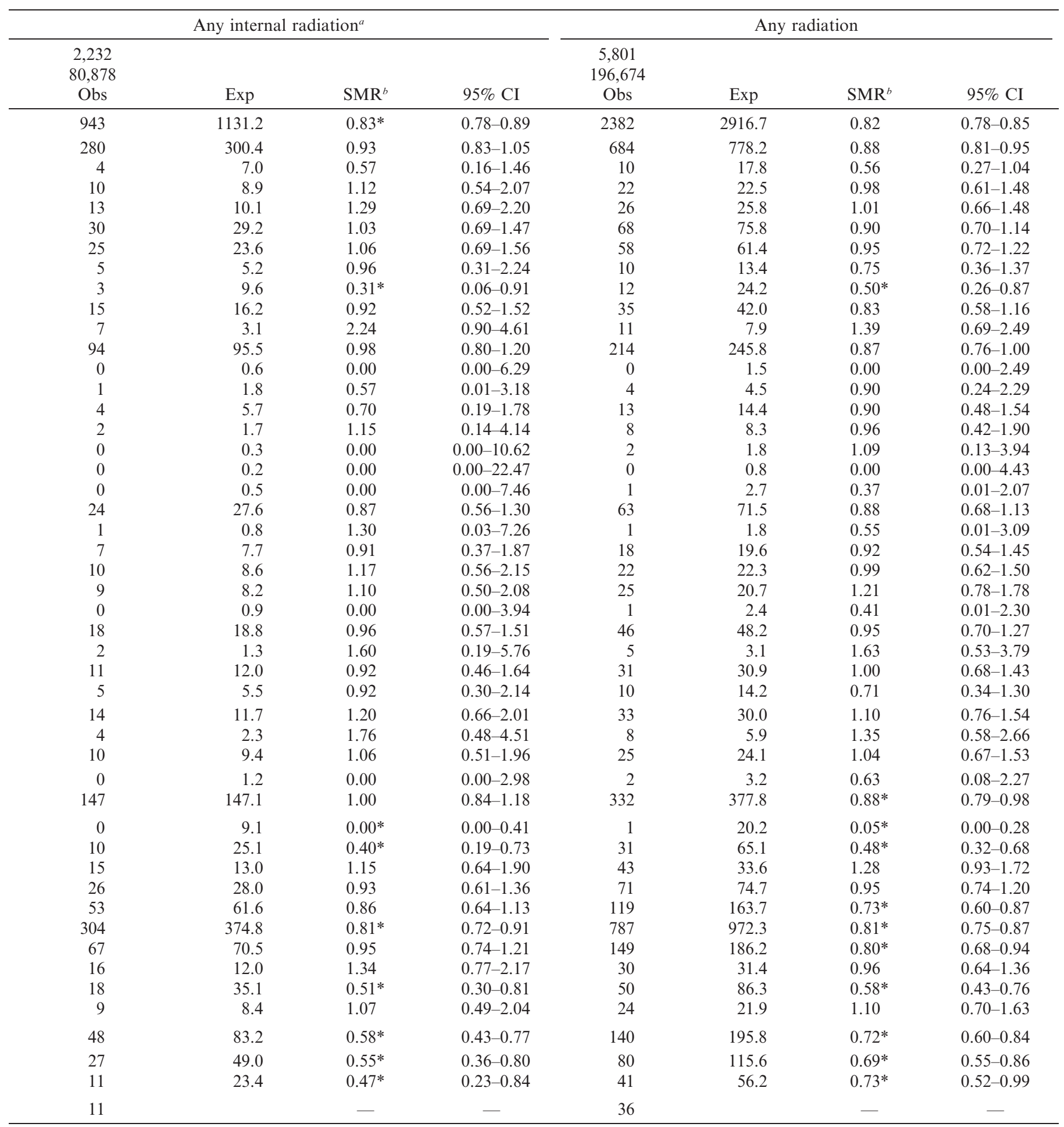

measurements indicated that their committed equivalent dose to any tissue was well below $10 \mathrm{mSv}$ (3). Among the 41,169 workers not monitored for radiation at Rocketdyne, $63.5 \%$ were alive in $2008,36.1 \%$ had died, $0.5 \%$ were lost to follow-up, and 3.6\% (or 1,478) had been monitored elsewhere for radiation (mean dose, $2.6 \mathrm{mSv}$ ).
The non-monitored workers were similar to the radiation workers with regard to race and years of follow-up but were more likely to be female, younger and hourly workers. Overall, 17,236 workers $(36.7 \%)$ were found to have died and 29,397 (62.6\%) to be alive as of December 31,2008 , and only $300(0.6 \%)$ were lost to follow-up 
TABLE 3

Observed and Expected ${ }^{a}$ Numbers of Deaths for Workers Monitored for Radiation over Categories of External Radiation Dose, Doses Lagged 10 Years for Solid Cancers and 2 Years for Leukemia

\begin{tabular}{|c|c|c|c|c|c|c|c|}
\hline $\begin{array}{r}\text { External radiation dose }(\mathrm{mSv}) \\
\text { No. of workers starting each dose interval } \\
\text { Person-years }\end{array}$ & $\begin{array}{l}\text { Not mo1 } \\
41,169 \\
1,392,648 \\
\text { Obs }\end{array}$ & hitored & $\begin{array}{c}<5 \\
5,762 \\
140,926 \\
\text { Obs }\end{array}$ & Exp & $\begin{array}{c}5- \\
1,277 \\
18,046 \\
\text { Obs }\end{array}$ & Exp & $\begin{array}{c}10- \\
1,221 \\
28,439 \\
\text { Obs }\end{array}$ \\
\hline All Malignant Neoplasms (140-208) & 4163 & 4438.4 & 419 & 487.7 & 80 & 90.2 & 143 \\
\hline Buccal Cavity \& Pharynx (140-149) & 75 & 99.6 & 5 & 11.3 & 1 & 2.0 & 3 \\
\hline Esophagus (150) & 98 & 116.9 & 11 & 13.9 & 3 & 2.6 & 7 \\
\hline Colon (153) & 338 & 349.5 & 40 & 38.3 & 2 & 7.2 & 14 \\
\hline Rectum (154) & 42 & 76.9 & 5 & 8.5 & 1 & 1.5 & 2 \\
\hline Biliary Passages \& Liver (155-156) & 94 & 139.0 & 9 & 15.3 & 2 & 2.8 & 1 \\
\hline Pancreas (157) & 246 & 239.2 & 17 & 26.3 & 5 & 4.9 & 12 \\
\hline Larynx (161) & 44 & 41.4 & 5 & 4.9 & 2 & 0.9 & 4 \\
\hline Bronchus, Trachea, \& Lung (162) & 1304 & 1346.0 & 135 & 153.0 & 25 & 28.7 & 41 \\
\hline All Uterine (Females only) (179-182) & 27 & 38.4 & 2 & 1.6 & 0 & 0.1 & 0 \\
\hline Cervix Uteri (180) & 9 & 17.5 & 0 & 0.7 & 0 & 0.1 & 0 \\
\hline Ovary \& Other Female Genital Organs (183-184) & 52 & 55.6 & 1 & 2.3 & 0 & 0.2 & 0 \\
\hline Prostate (Males only) (185) & 341 & 335.0 & 42 & 42.6 & 8 & 8.9 & 10 \\
\hline Testes \& Other Male Genital Organs (186-187) & 6 & 10.2 & 1 & 1.3 & 0 & 0.2 & 0 \\
\hline Kidney (189.0-189.2) & 106 & 105.8 & 11 & 12.2 & 1 & 2.3 & 3 \\
\hline Bladder \& Other Urinary $(188,189.3-189.9)$ & 98 & 113.4 & 14 & 13.6 & 3 & 2.7 & 5 \\
\hline Brain \& Central Nervous System (191-192) & 116 & 120.4 & 14 & 13.3 & 3 & 2.3 & 4 \\
\hline Thyroid \& Other Endocrine Glands (193-194) & 18 & 14.8 & 1 & 1.6 & 0 & 0.3 & 0 \\
\hline All Lymphatic Tissue (200-203) & 262 & 270.4 & 25 & 30.4 & 11 & 5.5 & 6 \\
\hline Hodgkin Lymphoma (201) & 19 & 19.1 & 4 & 2.2 & 0 & 0.3 & 0 \\
\hline Non-Hodgkin Lymphoma $(200,202)$ & 173 & 172.8 & 16 & 19.4 & 9 & 3.5 & 4 \\
\hline Multiple Myeloma (203) & 70 & 78.5 & 5 & 8.8 & 2 & 1.7 & 2 \\
\hline Diseases of Nervous System \& Sense Organs (320-389) & 446 & 427.1 & 46 & 47.1 & 8 & 8.2 & 13 \\
\hline Cerebrovascular Disease $(430-438)$ & 793 & 966.8 & 67 & 102.6 & 20 & 19.4 & 21 \\
\hline All Heart Disease $(390-398,404,410-429)$ & 4869 & 5372.4 & 503 & 609.5 & 87 & 113.7 & 152 \\
\hline Nonmalignant Respiratory Disease $(460-478,490-519)^{d}$ & 963 & 1026.5 & 88 & 114.2 & 23 & 22.2 & 30 \\
\hline Emphysema (492) & 164 & 177.3 & 17 & 19.8 & 5 & 3.7 & 6 \\
\hline Cirrhosis of Liver (571) & 302 & 500.0 & 38 & 57.0 & 4 & 9.2 & 3 \\
\hline Nephritis \& Nephrosis (580-589) & 120 & 123.7 & 15 & 13.7 & 4 & 2.5 & 5 \\
\hline All External Causes of Death (800-999) & 873 & 1234.7 & 113 & 138.8 & 10 & 18.4 & 15 \\
\hline Accidents $(850-949)$ & 515 & 726.7 & 63 & 82.4 & 7 & 10.7 & 9 \\
\hline Suicides (950-959) & 284 & 337.3 & 35 & 38.8 & 2 & 5.5 & 4 \\
\hline Unknown Causes of Death & 288 & & 28 & & 1 & & 5 \\
\hline
\end{tabular}

${ }^{a}$ Expected number of deaths is based on California population mortality rates.

${ }^{b} P$ values are two-sided since many causes of death, e.g., diabetes, have not been associated with radiation. For some sites with sparse numbers, the $P$ value was computed collapsing the dose categories. The trend test is provided to indicate the variation of observed and expected causes of death over categories of external radiation dose. The more optimal dose-response trends are found in Table 4, where internal radiation dose is included and the more powerful Cox regression analysis is used.

${ }^{c}$ Mesothelioma was not a codeable cause of death until 1999: ICD10 (C45). Before 1999, deaths from cancer of the pleura and peritoneum (ICD9 158.8, 158.9, 163) are used to approximate mesothelioma mortality.

${ }^{d}$ Excludes flu and pneumonia. 
MORTALITY AMONG ROCKETDYNE WORKERS

TABLE 3

Extended

\begin{tabular}{|c|c|c|c|c|c|c|c|c|c|c|}
\hline$\frac{\operatorname{Exp}}{558.9}$ & $\begin{array}{c}50- \\
284 \\
4,791 \\
\text { Obs } \\
66\end{array}$ & $\begin{array}{l}\text { Exp } \\
94.9\end{array}$ & $\begin{array}{c}100- \\
149 \\
2,841 \\
\text { Obs } \\
45\end{array}$ & $\begin{array}{l}\text { Exp } \\
49.3\end{array}$ & $\begin{array}{c}\geq 200 \\
66 \\
1,631 \\
\text { Obs } \\
26\end{array}$ & \multicolumn{3}{|c|}{$\begin{array}{l}\text { Total monitored } \\
5,801 \\
196,674\end{array}$} & \multicolumn{2}{|c|}{$\begin{array}{c}\text { Trend test } P \text { value } \\
\text { (directional) }\end{array}$} \\
\hline 151.9 & 17 & 25.2 & 16 & 14.0 & 9 & 9.0 & 684 & 778.2 & 0.41 & $(-)$ \\
\hline 3.4 & 1 & 0.6 & 0 & 0.3 & 0 & 0.2 & 10 & 17.8 & 0.76 & $(-)$ \\
\hline 4.5 & 1 & 0.8 & 0 & 0.4 & 0 & 0.3 & 22 & 22.5 & 0.36 & $(+)$ \\
\hline 12.1 & 1 & 2.0 & 1 & 1.1 & 0 & 0.7 & 58 & 61.4 & 0.60 & $(-)$ \\
\hline 2.5 & 1 & 0.4 & 1 & 0.2 & 0 & 0.1 & 10 & 13.4 & 0.08 & $(+)$ \\
\hline 4.6 & 0 & 0.8 & 0 & 0.5 & 0 & 0.3 & 12 & 24.2 & 0.14 & $(-)$ \\
\hline 8.2 & 1 & 1.4 & 0 & 0.8 & 0 & 0.5 & 35 & 42.0 & 0.62 & $(-)$ \\
\hline 1.5 & 0 & 0.3 & 0 & 0.1 & 0 & 0.1 & 11 & 7.9 & 0.30 & $(+)$ \\
\hline 48.6 & 1 & 8.0 & 7 & 4.6 & 5 & 2.9 & 214 & 245.8 & 0.29 & $(-)$ \\
\hline 0.1 & 0 & 0.0 & 0 & 0.0 & 0 & 0.0 & 2 & 1.8 & 0.73 & $(+)$ \\
\hline 0.1 & 0 & 0.0 & 0 & 0.0 & 0 & 0.0 & 0 & 0.8 & 0.54 & $(-)$ \\
\hline 0.2 & 0 & 0.0 & 0 & 0.0 & 0 & 0.0 & 1 & 2.7 & 0.33 & $(-)$ \\
\hline 15.2 & 0 & 2.6 & 2 & 1.3 & 1 & 0.9 & 63 & 71.5 & 0.16 & $(-)$ \\
\hline 0.2 & 0 & 0.0 & 0 & 0.0 & 0 & 0.0 & 1 & 1.8 & 0.80 & $(-)$ \\
\hline 3.9 & 1 & 0.6 & 2 & 0.4 & 0 & 0.2 & 18 & 19.6 & 0.79 & $(+)$ \\
\hline 4.6 & 0 & 0.8 & 0 & 0.4 & 0 & 0.3 & 22 & 22.3 & 0.98 & $(-)$ \\
\hline 3.8 & 4 & 0.6 & 0 & 0.4 & 0 & 0.2 & 25 & 20.7 & 0.13 & $(+)$ \\
\hline 0.4 & 0 & 0.1 & 0 & 0.0 & 0 & 0.0 & 1 & 2.4 & 0.26 & $(-)$ \\
\hline 9.2 & 2 & 1.6 & 1 & 0.9 & 1 & 0.6 & 46 & 48.2 & 0.81 & $(+)$ \\
\hline 0.4 & 0 & 0.1 & 0 & 0.0 & 1 & 0.0 & 5 & 3.1 & 0.07 & $(+)$ \\
\hline 6.0 & 2 & 1.0 & 0 & 0.6 & 0 & 0.4 & 31 & 30.9 & 0.99 & $(+)$ \\
\hline 6.4 & 1 & 1.1 & 0 & 0.5 & 1 & 0.4 & 43 & 33.6 & 0.03 & $(+)$ \\
\hline 14.7 & 0 & 2.6 & 2 & 1.2 & 2 & 0.9 & 71 & 74.7 & 0.55 & $(-)$ \\
\hline 31.9 & 7 & 5.5 & 4 & 2.6 & 0 & 1.8 & 119 & 163.7 & 0.65 & $(-)$ \\
\hline 189.5 & 24 & 32.4 & 13 & 16.3 & 8 & 10.9 & 787 & 972.3 & 0.01 & $(-)$ \\
\hline 37.9 & 4 & 6.4 & 4 & 3.3 & 0 & 2.3 & 149 & 186.2 & 0.11 & $(-)$ \\
\hline 6.1 & 0 & 1.0 & 2 & 0.5 & 0 & 0.3 & 30 & 31.4 & 0.63 & $(+)$ \\
\hline 15.2 & 4 & 2.5 & 1 & 1.5 & 0 & 0.9 & 50 & 86.3 & 0.44 & $(-)$ \\
\hline 4.3 & 0 & 0.7 & 0 & 0.4 & 0 & 0.3 & 24 & 21.9 & 0.98 & $(+)$ \\
\hline 29.3 & 2 & 5.0 & 0 & 2.8 & 0 & 1.6 & 140 & 195.8 & 0.13 & $(-)$ \\
\hline 17.0 & 1 & 2.9 & 0 & 1.6 & 0 & 1.0 & 80 & 115.6 & 0.22 & $(-)$ \\
\hline 8.9 & 0 & 1.5 & 0 & 0.9 & 0 & 0.5 & 41 & 56.2 & 0.06 & $(-)$ \\
\hline & 1 & & 0 & & 1 & & 36 & & & \\
\hline
\end{tabular}

(Fig. 1). Cause of death was missing for only 324, or $1.9 \%$ of the deaths occurring within the United States.

Dosimetry linkages with Landauer Inc., DOE REMS and NRC REIRS databases matched 247 unique workers, of whom 157 had a measurable dose after 1999 through 2008 (mean cumulative dose, $0.6 \mathrm{mSv}$ ). This small dose to such a small number of workers did not appreciably change the mean external dose for the entire population; i.e., the mean of $13.50 \mathrm{mSv}$ increased only to $13.52 \mathrm{mSv}$. Similarly, for the 209 workers alive in 1999 with meaningful prior intakes of radionuclides, their mean cumulative lung dose over the next 9 years was only $0.013 \mathrm{mSv}$. Again, this did not meaningfully change the previous mean cumulative lung dose, which 
TABLE 4

Internal Cohort Dose-Response Trend Analyses ${ }^{a}$ and Relative Risks (RR) for Selected Cancers over Categories of Organ-Specific Radiation Doses ${ }^{b}$ with Doses Lagged 10 Years for Solid Cancer and 2 Years for Leukemia

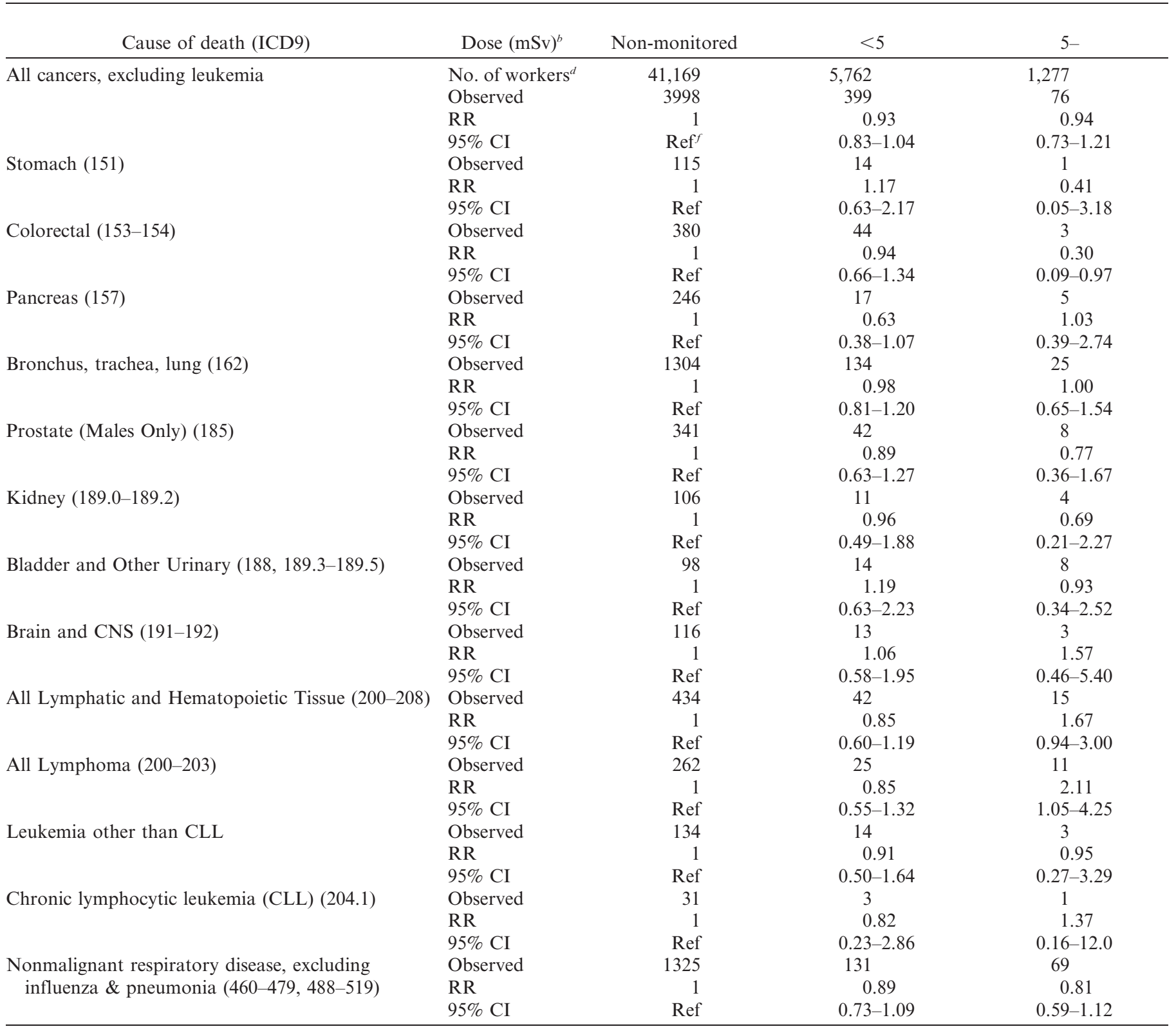

${ }^{a}$ All models adjusted for year of birth, year of hire, sex, internal monitoring, pay type (hourly/salary), duration of employment, and work as a test stand mechanic. The time variable for the hazard function is age at observation. All workers were followed for vital status through December 2008.

${ }^{b}$ Dose categories include external radiation doses received before, during, and after employment at Rocketdyne. External radiation doses plus any internal doses from the intake of radionuclides are included for all organs except the "all cancer excluding leukemia" category where the cancers are distributed and analyzed over categories of external dose.

${ }^{c} P$ value for test for linear trend in the relative risk (i.e., hazard ratio) computed over categories of organ dose. $(+)$ denotes a positive trend, $(-)$ denotes a negative trend. $P$ values are one-sided.

${ }^{d}$ Number of workers starting the dose interval. Although the number of workers differed across categories of dose because of the differing contribution of internal radiation dose to different organs, only the categories of lung dose and bone marrow dose change appreciably; i.e. for lung the numbers starting each lung dose category are 5,762,1,258,1,314, 387 and 106, and for leukemia other than CLL, the numbers starting each bone marrow dose category are 5,762, 1,325, 1,257 and 334 .

${ }^{e}$ Because of small numbers, convergence over the full range of dose categories was possible only for "all cancers, excluding leukemia." For lung cancer, dose categories $50 \mathrm{mSv}$ and 100-199 mSv were combined; dose categories 5-10 mSv and 10-49 mSv were combined for kidney cancer and for non-malignant respiratory disease. For all sites other than "all cancers, excluding leukemia" and lung cancer, the highest dose category was $\geq 50 \mathrm{mSv}$.

${ }^{f}$ Referent category. 
TABLE 4

Extended

\begin{tabular}{|c|c|c|c|c|}
\hline $10-$ & $50-$ & $100-$ & $\geq 200$ & $\begin{array}{c}\text { Trend test }{ }^{c} P \text { value } \\
\text { (direction) }\end{array}$ \\
\hline 1,221 & 284 & 149 & 66 & \\
\hline 134 & 16 & 15 & 8 & $0.41(-)$ \\
\hline 0.99 & 0.73 & 1.24 & 1.11 & \\
\hline $0.80-1.23$ & $0.44-1.20$ & $0.73-2.10$ & $0.54-2.27$ & \\
\hline 8 & 3 & - & - & $0.27(+)$ \\
\hline 2.02 & 2.54 & - & - & \\
\hline $0.77-5.31$ & $0.65-9.92$ & - & - & \\
\hline 16 & 4 & - & - & $0.18(-)$ \\
\hline 0.89 & 0.69 & - & - & \\
\hline $0.47-1.70$ & $0.23-2.03$ & - & - & \\
\hline 12 & 1 & - & - & $0.18(-)$ \\
\hline 1.48 & 0.40 & - & - & \\
\hline $0.69-3.18$ & $0.05-3.08$ & - & - & \\
\hline 41 & 7 & - & 7 & $0.42(-)$ \\
\hline 0.93 & 0.51 & - & 1.64 & \\
\hline $0.63-1.36$ & $0.24-1.12$ & - & $0.74-3.65$ & \\
\hline 10 & 3 & - & - & $0.33(-)$ \\
\hline 0.54 & 0.49 & - & - & \\
\hline $0.25-1.14$ & $0.15-1.67$ & - & - & \\
\hline - & 3 & - & - & $0.13(+)$ \\
\hline - & 2.63 & - & - & \\
\hline - & $0.64-10.7$ & - & - & \\
\hline - & - & - & - & $0.21(-)$ \\
\hline - & - & - & - & \\
\hline - & - & - & - & \\
\hline 4 & 4 & - & - & $0.37(+)$ \\
\hline 1.30 & 4.21 & - & - & \\
\hline $0.41-4.09$ & $1.27-14.0$ & - & - & \\
\hline 15 & 7 & - & - & $0.25(+)$ \\
\hline 0.97 & 1.43 & - & - & \\
\hline $0.52-1.79$ & $0.62-3.30$ & - & - & \\
\hline 6 & 4 & - & - & $0.34(+)$ \\
\hline 0.66 & 1.38 & - & - & \\
\hline $0.26-1.66$ & $0.45-4.17$ & - & - & \\
\hline 6 & 2 & - & - & $0.44(+)$ \\
\hline 1.10 & 1.16 & - & - & \\
\hline $0.40-3.05$ & $0.24-5.52$ & - & - & \\
\hline 3 & 1 & - & - & $0.22(+)$ \\
\hline 2.42 & 2.70 & - & - & \\
\hline $0.49-12.0$ & $0.27-27.4$ & - & - & \\
\hline - & 13 & - & - & $0.07(-)$ \\
\hline - & 0.56 & - & - & \\
\hline - & $0.31-1.03$ & - & - & \\
\hline
\end{tabular}

remained essentially the same at $19.0 \mathrm{mSv}$. The negligible contribution of radiation doses received after 1999 reflects (1) the small number of former Rocketdyne workers employed in radiation activities after 1999, (2) the low radiation exposures received by most current workers in the nuclear industry, and (3) the low radioactivity of substances still remaining in the body after so many years had passed since intake.

Table 2 presents the SMRs for over 40 causes of death for the 5,743 workers monitored for external radiation and the 2,232 workers monitored for internal radiation. Overall, 2,382 deaths were observed and 2,916.7 were expected (SMR 0.82; 95\% CI 0.78-0.85). There were 684 deaths from cancer and 778.2 expected (SMR 0.88; 95\% CI 0.81-0.95). There was no statistically significant elevation among the 132 SMRs presented. For all radiation workers taken together, $26 \mathrm{SMRs}$ for specific cancer deaths are presented: 12 were above or consistent with 1.0 and 14 were below 1.0.

Lung cancer was not increased (SMR 0.87; 95\% CI $0.76-1.00, n=214)$, nor were other sites of a priori interest, e.g., cancers of the liver (SMR 0.50, $n=12$ ), bone (SMR 0.0), esophagus (SMR 0.98, $n=22$ ) and kidney (SMR 0.92, $n=18$ ). Nonmalignant kidney disease, i.e., nephritis and nephrosis (SMR 1.10, $n=24$ ), also was not significantly increased. All leukemias 
combined were slightly elevated but not significantly (SMR 1.10, $n=33$ ). The SMR for chronic lymphocytic leukemia (CLL) was higher (SMR 1.35, $n=8$ ) than the SMR for the other leukemias (SMR 1.04, $n=25$ ). No type or subcategory of leukemia was significantly increased. Significant deficits were seen for heart disease, diabetes, cerebrovascular disease, cirrhosis of the liver, nonmalignant respiratory disease and all external causes of death.

Table 3 presents trends in the observed to expected numbers of cancer deaths over categories of external radiation dose. For 27 individual cancers, 12 of the trends were positive and 15 were negative, a distribution consistent with chance. The trends were computed using both the non-monitored workers and the $<5 \mathrm{mSv}$ group as the referent category with similar results (data not shown). The seven categories of external radiation dose included exposures received before, during and after employment at Rocketdyne. Among the 284 workers who accumulated $50 \mathrm{mSv}$ or more, 42 cancer deaths occurred and 48.2 were expected. Few workers, only 66, had cumulative external doses greater than or equal to $200 \mathrm{mSv}$, and only 9 cancer deaths (compared to 9.0 expected) occurred among these workers. The trends for all cancers combined and for lung cancer were not significant. A significant positive trend $(P=0.03,1$ sided) was seen for stomach cancer. A slight trend in all leukemias combined ( $P=0.13,1$-sided) was related to a positive trend in CLL $(P=0.06,1$-sided $)$, a type of leukemia not considered inducible by radiation (14). There was no dose-response trend for the non-CLL leukemias, which are known to be associated with radiation $(P=0.30,1$-sided $)$. The 58 workers who were monitored only for internal intakes of radionuclides were assigned a zero external dose. Excluding them from the analyses did not affect the results presented in Table 3. These Poisson trend statistics for indirectly standardized rates can be regarded as rough approximations to the more robust methods used for Table 4 , i.e., Cox time-dependent regression analyses incorporating internal radiation dose to specific organs and adjusting for potentially important confounding variables.

Table 4 presents internal cohort dose-response analyses for 14 cancer categories and nonmalignant respiratory disease based on Cox proportional hazards models combining external radiation dose with organ-specific internal radiation dose. These causes of cancer death were selected because of a priori interest as radiosensitive sites, e.g., leukemia or as sites of uranium deposition or exposure, e.g., lung and kidney, or if the total number of deaths was at least 20, e.g., prostate.

There were no significant increases seen for all solid cancers taken together, lung cancer or any other cancer (Table 4). Nonsignificant increasing trends were seen for cancers of the stomach, kidney, brain and other central nervous system, leukemia and lymphomas. Nonsignificant decreasing trends were seen for cancers of the colorectum, lung, pancreas, prostate and bladder and for nonmalignant respiratory disease. Stomach cancer did not show a significant trend $(P=0.27,1$-sided $)$. The risk of leukemia (excluding CLL) tended to increase over increasing categories of radiation dose to active bone marrow but the trend was not significant $(P=0.44)$. The relative risks (i.e., hazard ratios) for CLL were consistently higher than those for the other leukemias (excluding CLL), which is of interest given that radiation has not been found to increase the risk of CLL (14), but the trend was not statistically significant $(P=0.22)$. The relative risk $(\mathrm{RR})$ at $100 \mathrm{mSv}$ was computed for the standard Cox model, which includes all the adjustment factors. The RR at $100 \mathrm{mSv}$ for all cancers (excluding leukemia), lung cancer and leukemia (excluding CLL) were estimated to be 0.98 (95\% CI $0.82-1.17), 1.01$ (95\% CI 0.89-1.16) and 1.06 (95\% CI $0.50-2.23)$, respectively. For CLL, the RR at $100 \mathrm{mSv}$ was 1.36 (95\% CI $0.63-2.89)$.

Table 5 shows the relative risk (RR) for lung cancer over categories of external and internal dose for 5,801 radiation workers. The referent group was taken as the 3,817 workers with cumulative lung dose $<5 \mathrm{mSv}$ for both external and internal radiation. Of the $15 \mathrm{RRs}$ presented, 7 were above unity and 8 were below unity, and no RR was statistically significant. Among the 1,984 workers with $>5 \mathrm{mSv}$ external and/or $>5 \mathrm{mSv}$ internal dose to the lung, the RR was 1.15 (95\% CI 0.88-1.51). The numbers are too small to make strong conclusions about the joint effects of external and internal exposures; i.e., there were only 6 lung cancers among workers with $>5 \mathrm{mSv}$ from both external and internal radiation.

\section{DISCUSSION}

An additional 9 years of follow-up uncovered no consistent associations between cancer and radiation within the Rocketdyne workforce. Comparisons with the general population of California revealed a healthy workforce with overall death rates significantly low (SMR 0.82). Cancers of a priori interest, e.g., lung, leukemia and kidney, were not significantly associated with radiation. The study is unique in capturing occupational doses received both before and after employment at Rocketdyne and in computing organ specific doses from available bioassay monitoring records on radionuclide intake. The study is limited by the small sample size $(n=5,801)$ and relatively low cumulative occupational doses. Nonetheless, the period of observation was up to 60 years (mean, 33.9 years), and RRs at $100 \mathrm{mSv}$ as low as 1.16 for lung cancer and 1.17 for all cancers (excluding leukemia) could be excluded with $95 \%$ confidence. The RR at $100 \mathrm{mSv}$ for leukemia other than CLL (RR 1.06) was not statistically 
TABLE 5

Relative Risk (RR) ${ }^{a}$ for Lung Cancer over Categories of External and Internal Dose to Lung with Doses Lagged 10 Years

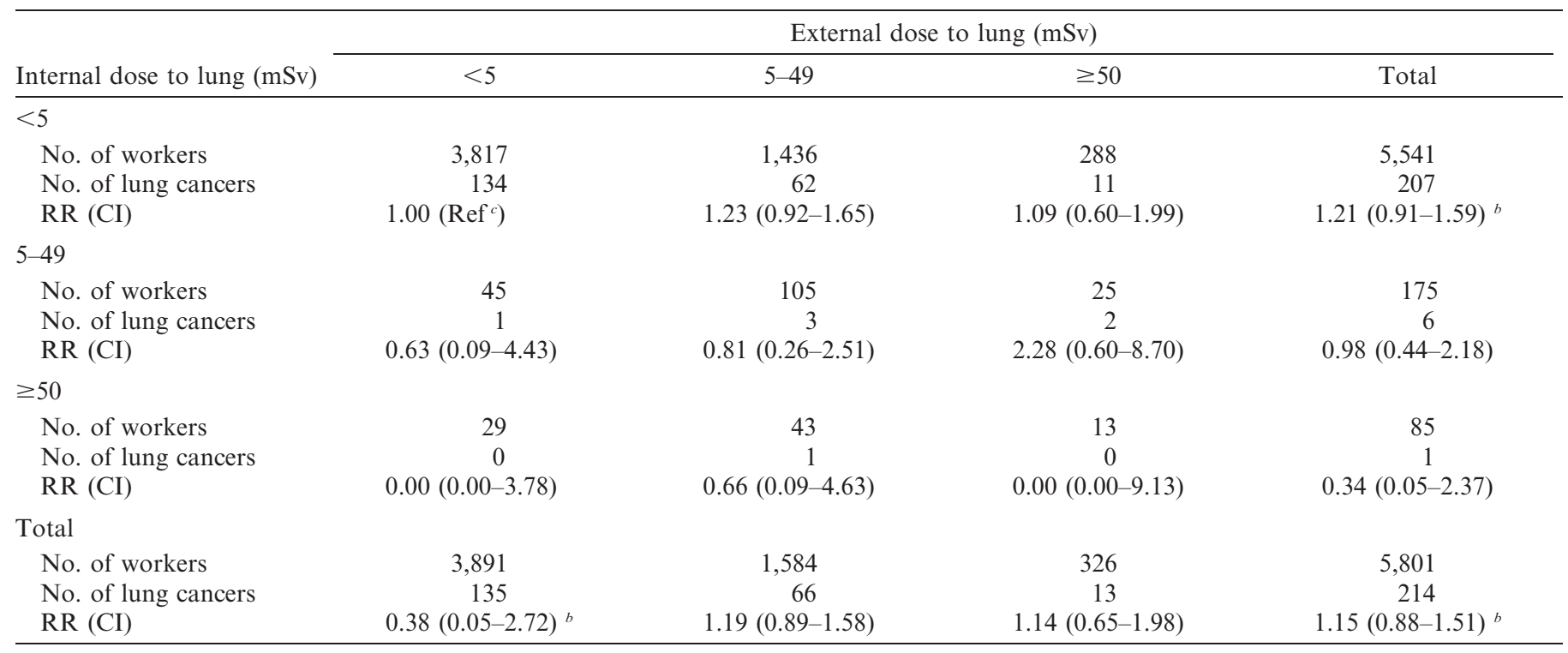

${ }^{a}$ Referent category for all RRs is external dose $<5 \mathrm{mSv}$ and internal dose $<5 \mathrm{mSv}$ to lung.

${ }^{b} \mathrm{RR}$ calculated after excluding referent group. That is, the referent group is compared with the 1,724 workers with $<5 \mathrm{mSv}$ internal dose who developed 73 lung cancers (RR 1.21); with the 74 workers with $<5 \mathrm{mSv}$ external dose who developed 1 lung cancer (RR 0.38 ); and the 1984 workers with $>5 \mathrm{mSv}$ external and/or $>5 \mathrm{mSv}$ internal dose who developed 80 lung cancers (RR 1.15).

${ }^{c}$ Referent category.

significant but was consistent with predictions from other radiation studies, though somewhat lower (14). The increase in the number of deaths during the additional 9 years of follow-up increased the precision of the radiation risk estimates. Though slightly lower, the radiation risk estimates were similar and statistically compatible with those reported previously (1).

Low risks for heart disease and cerebrovascular disease are often reported in occupational studies and are ascribed to the "healthy worker effect" associated with selection for employment and for continued employment (15-18). The healthy worker effect often diminishes with length of time since first employed (18). This diminution of the healthy worker effect was seen in the current study, with the SMRs for heart disease increasing from 0.78 to 0.81 and for cerebrovascular disease from 0.71 to 0.73 . The SMRs for cancer, however, decreased from 0.90 to 0.88 with the additional 9 years of follow-up.

As expected when conducting multiple statistical analyses of numerous disease end points, some elevated cancer risk estimates are expected to occur by chance alone and should be considered in the context of findings from earlier worker studies. A significant positive trend in the SMRs for stomach cancer and a positive trend in the RRs for stomach cancer, for example, were seen over categories of radiation dose in comparison with general population rates and in comparison with the non-monitored workers, respectively. The overall SMR for stomach cancer $(1.01, n=$
26), however, was not elevated among radiation workers, and the significant trends appeared to be related in part to a significantly low SMR among the "not monitored" group (SMR 0.80; 95\% CI 0.66-0.96). There is little evidence suggesting that uranium workers (23) or other radiation workers are at increased risk for stomach cancer, whereas increases are seen among atomic bomb survivors and some patient groups treated with radiotherapy (14). Helicobacter pylori infection is the strongest and most important risk factor for stomach cancer (19). Other risk factors include ethnicity, diet, tobacco use and family history.

\section{Uranium}

The 2,232 workers monitored for intakes of radionuclides had similar patterns of risk as those monitored for external radiation. Although intakes were detected for some 14 different radionuclides, intake of uranium enriched in uranium-235 was the most frequent. Some workers received high lung doses $(>3 \mathrm{~Sv})$, but the number of workers was apparently too small to discern a radiation effect had there been one; i.e., the $\mathrm{RR}$ at $100 \mathrm{mSv}$ was estimated to be 1.01 (95\% CI $0.89-1.16$ ). Because of its long half-life, solubility properties and lack of significant associations in epidemiological studies, uranium has not been classified as a human carcinogen $(14,20)$. The National Research Council Committee on Toxicology (21) recently evaluated 16 studies of uranium workers and concluded "that the 
preponderance of evidence indicates that there is not an appreciable risk of cancer in humans exposed to uranium." This assessment is consistent with previous evaluations by the UK Royal Society (22), the IARC (20) and the Institute of Medicine (23). Uranium from reprocessing of irradiated fuel is more radioactive than natural uranium because of contaminants such as uranium-232, which has a half-life of 72 years (24), but there presumably was little to no exposure to uranium232 among Rocketdyne workers. Recent studies of uranium millers report no consistent associations between duration of employment and excess cancers $(25,26)$. Studies of workers with estimates of organ doses from uranium intakes also fail to find clear evidence of dose-response relationships $(1,27)$.

\section{Kidney Disease}

The possible chemical toxicity of uranium, a heavy metal, is considered more important for human health than the risk of cancer from its radioactive properties (28). Ingesting large amounts of uranium might cause kidney damage because the kidney is involved in removing uranium from the body and is a site of elevated accumulation of uranium. However, renal damage observed in humans after high intakes of uranium generally appears to have been transient (29). Among Rocketdyne workers, the highest doses were estimated for workers exposed to airborne uranium aluminide $\left(\mathrm{UAl}_{\mathrm{x}}\right)$ during the fabrication of reactor fuel plates. Most types of uranium are soluble and leave the body within a few days, but inhaled $\mathrm{UAl}_{\mathrm{x}}$ did not leave the body quickly due to an unexpected delayed dissolution of the inhaled material (2). Among the 2,232 workers monitored for intakes of enriched uranium and other radionuclides, 9 deaths due to non-malignant kidney disease occurred compared with 8.4 expected (SMR 1.07; 95\% CI 0.49-2.04), and 7 deaths due to kidney cancer occurred compared with 7.7 expected. The absence of significant increases in kidney disease is consistent with studies of workers processing uranium that also failed to reveal consistent evidence of an excess of chronic renal failure or any cancer that could be attributed to uranium intake $(21,22,30)$. Kidney damage of clinical importance has rarely if ever been observed in workers exposed to high levels of soluble uranium compounds (31) or in Gulf War veterans exposed to depleted uranium from embedded shrapnel (32).

\section{Leukemia}

A slight increase in leukemia other than CLL was observed that was consistent with, though lower than, statistical predictions from other radiation studies; i.e., the RR at $100 \mathrm{mSv}$ for all leukemia excluding CLL was 1.06 (95\% CI 0.50-2.23). However, a similar nonsignificant increase in CLL (RR 1.36; 95\% CI 0.63-2.89), a malignancy not thought to be caused by radiation (14), tempers a causal interpretation.

\section{Strengths and Limitations}

Strengths of our occupational study include the cohort design, the long follow-up of up to 60 years, the capturing of occupational doses received both before and after employment at Rocketdyne, the computation and inclusion of organ specific doses from intakes of radionuclides, the complete roster of all workers employed in a variety of research programs (including nuclear fuel fabrication, spent nuclear fuel decladding, and reactor operation and disassembly), and the large number of nonexposed workers at the same facilities available for comparison. Other strengths include the low percentage of workers who were lost to follow-up $(0.6 \%)$ and the low percentage of deaths for which a specific cause was not available $(1.9 \%)$.

Limitations of the study include the relatively small number of workers, possible errors in dosimetry, and the incomplete knowledge of confounding factors such as smoking history. Pay type (hourly/salary), however, was adjusted for in the analyses as a surrogate measure of socioeconomic class and indirectly for tobacco consumption as supported by a small survey of 300 workers (1). Further, the overall SMR for smoking-related cancers was significantly low at 0.88 (95\% CI $0.79-0.98)$, suggesting a low cigarette consumption compared with the general population. The study is of mortality and not incidence of disease, for which the number of events and quality of diagnoses would be expected to be higher. Most of the diseases of interest, e.g., lung cancer and leukemia, however, have a high fatality rate over the years of study so that mortality would reflect incidence fairly closely. Diseases that have a low fatality rate can be evaluated in mortality studies, although the statistical power to identify a significant increase in risk might be lower than for an incidence survey because of the smaller number of events. The relatively low cumulative dose, even incorporating doses received both before and after Rocketdyne employment, limits the ability of the study to detect an effect had there been one. Nonetheless, the mean dose from external radiation of $13.5 \mathrm{mSv}$ (maximum $1 \mathrm{~Sv}$ ) and the mean lung dose from external and internal radiation combined of $19.0 \mathrm{mSv}$ (maximum 3.6 Sv) are comparable to the mean doses from the recent, albeit much larger, international study of radiation workers with mean external dose of $19.4 \mathrm{mSv}$ and less than $0.1 \%$ receiving cumulative doses over $0.5 \mathrm{~Sv}$ (33), and the mean followup of Rocketdyne workers (33.9 years) was longer than in the 15-country international study (12.7 years). The recent study of workers in the UK National Registry for Radiation Workers included 171,541 persons with mean dose of $24.9 \mathrm{mSv}(6 \%$ over $0.1 \mathrm{~Sv})$ and mean followup of 22.7 years (34). No worker study, however, has 
found significant increases of cancer below $0.2 \mathrm{~Sv}$, in large part because of the statistical uncertainties associated with such low-dose exposures (35).

Personnel monitoring devices and bioassay measurements provide estimates of radiation dose in ways far superior to those possible for chemical or other agents found in the workplace, but such estimates are nonetheless subject to random error and to systematic biases (36). "Random error in the measurement of dose is independent across workers and tends to reduce the power for detecting effects. Systematic error or bias can lead to spurious results. Systematic biases can include inadequate collection of prior or subsequent radiation work histories, inadequate treatment of the intake of radionuclides and underestimation of neutron exposures. Other sources of possible bias include medical radiation procedures, natural background radiation and even conventions in recording radiation dose, e.g., for doses below a minimum detectable level (MDL) of the measurement device setting the dose to either zero or to the MDL, or assigning a value for missing dose as the maximum allowed by regulation during the reporting period. Measurement uncertainties include those associated with differences in photon energy, exposure geometry and type of dosimeter" (3). The magnitude of the major sources of potential bias was minimized by our success in capturing practically all radiation exposures received elsewhere and by applying the latest ICRP models to compute organ doses after internal intakes of radionuclides $(2,3)$. Inadequate or improper treatment of worker exposures would likely have underestimated organ doses and overestimated derived risks per unit dose.

In summary, the long-term follow-up of Rocketdyne workers exposed to external radiation and internal radiation, primarily enriched uranium, as early as 1948 has failed to reveal significant excesses of cancers or nonmalignant diseases. Although limited by a relatively small sample size and low cumulative occupational doses, the workers were followed for up to 60 years, and RRs at $100 \mathrm{mSv}$ as low as 1.16 could be excluded with 95\% confidence for lung cancer, 1.17 for all cancers excluding leukemia and 2.23 for leukemia other than CLL. Larger combined studies of early workers in the United States using similar methodologies are warranted to refine and clarify radiation risks after protracted exposures (37).

\section{ACKNOWLEDGMENTS}

The extended follow-up was funded by a Discovery Grant from the Vanderbilt-lngram Cancer Center (Center no. 404-357-9682), a research grant from the U.S. Department of Energy (Grant no. DESC0004307), and a contract between the U.S. Department of Energy and Oak Ridge Associated Universities (Contract no. DE-AC0506OR23100). The initial study was supported in part by a competitive contract from The Boeing Company and was conducted with cooperation from the UAW (United Automobile, Aerospace and Agricultural Implement Workers of America) and from Oak Ridge Institute for Science and Education (ORISE) through an interagency agreement with the U.S. Department of Energy (DOE). ORISE is managed by Oak Ridge Associated Universities under DOE contract number DE-AC05-00OR22750. We thank again the contributors to the initial study: the Department of Energy (Ms. Nimi Rao), the Nuclear Regulatory Commission (Ms. Rosemary Hogan and Ms. Sheryl Burrows), SAIC (Mr. Derek A. Hagemeyer, now with ORISE), the U.S. Army Radiation Standards and Dosimetry Laboratory (William S. Harris, Jr., CHP) and the U.S. Air Force Radiation Surveillance Division, Air Force Institute for Operational Health (Gerald Achenbach and Mike Klueber) for providing linkages with their respective dosimetry files. We acknowledge again the helpful advice provided during the initial study by Ms. Barbara Brooks (former CEDR Program Coordinator, DOE), Mrs. Judy McLaughlin (Rocketdyne, The Boeing Company), and James G. Barnes, CHP (Radiation Safety Office, Rocketdyne, The Boeing Company). The contributions and guidance provided previously by the Rocketdyne Worker Health Science Committee are also gratefully acknowledged: Dr. John Peters (deceased, University of Southern California, Chairman), Dr. Scott Davis (University of Washington), Dr. John Dement (Duke University), Dr. Karl Kelsey (Harvard School of Public Health, now at Brown University), Dr. Jack Siemiatycki (University of Montreal), and Dr. Laura Welch (George Washington University). The results presented herein represent the conclusions and opinions solely of the authors. Their publication does not imply endorsement by The Boeing Company, the UAW, Vanderbilt University or any of the acknowledged agencies or persons.

Received: November 5, 2010; accepted: January 6, 2011; published online: March 7, 2011

\section{REFERENCES}

1. J. D. Boice Jr., S. S. Cohen, M. T. Mumma, E. D. Ellis, K. F. Eckerman, R. W. Leggett, B. B. Boecker, A. B. Brill and B. E. Henderson, Mortality among radiation workers at Rocketdyne (Atomics International), 1948-1999. Radiat. Res. 166, 98-115 (2006).

2. R. W. Leggett, K. F. Eckerman and J. D. Boice Jr., A respiratory model for uranium aluminide based on occupational data. $J$. Radiol. Prot. 25, 405-416 (2005).

3. J. D. Boice Jr., R. W. Leggett, E. D. Ellis, P. W. Wallace, M. Mumma, S. S. Cohen, A. B. Brill, B. Chadda, B. B. Boecker and K. F. Eckerman, A comprehensive dose reconstruction methodology for former Rocketdyne/Atomics International radiation workers. Health Phys. 90, 409-430 (2006).

4. K. M. Campbell, D. Deck and A. Krupski, Record linkage software in the public domain: a comparison of Link Plus, The Link King, and a 'basic' deterministic algorithm. Health Informatics J. 14. 5-15 (2008).

5. R. W. Leggett and K. F. Eckerman, A systemic biokinetic model for polonium. Sci. Total Environ. 275, 109-125 (2001).

6. D. M. Taylor and R. W. Leggett, A generic biokinetic model for predicting the behaviour of the lanthanide elements in the human body. Radiat. Prot. Dosimetry 205, 193-198 (2003).

7. J. Harrison, R. Leggett, D. Lloyd, A. Phipps and B. Scott, Polonium-210 as a poison. J. Radiol. Prot. 27, 17-40 (2007).

8. G. M. Marsh, A. O. Youk, R. A. Stone, S. Sefcik and C. Alcorn, OCMAP-PLUS: A program for the comprehensive analysis of occupational cohort data. J. Occup. Environ. Med. 40, 351-362 (1998).

9. D. R. Cox, Regression models and life-tables. J. R. Stat. Soc. B 34, 187-220 (1972).

10. N. E. Breslow, J. H. Lubin, P. Marek and D. Langholz, Multiplicative models and cohort analysis. J. Am. Stat. Assoc. 78, 1-12 (1983).

11. D. J. Lee, W. LeBlanc, L. E. Fleming, O. Gomez-Marin and T. Pitman, Trends in US smoking rates in occupational groups: the 
National Health Interview Survey 1987-1994. J. Occup. Environ. Med. 46, 538-548 (2004).

12. J. D. Boice Jr., D. E. Marano, S. S. Cohen, M. T. Mumma, W. J. Blot, A. B. Brill, J. P. Fryzek, B. E. Henderson and J. K. McLaughlin, Mortality among Rocketdyne workers who tested rocket engines, 1948-1999. J. Occup. Environ. Med. 48, 10701092 (2006).

13. R. Cox and A. M. Kellerer, A current view on radiation weighting factors and effective dose. In Relative Biological Effectiveness (RBE), Quality Factor $(Q)$, and Radiation Weighting Factor (WR). Publication 92, Annals of the ICRP, Vol. 33, No. 1-4, Pergamon Press, London, 2003.

14. United Nations Scientific Committee on the Effects of Atomic Radiation (UNSCEAR), Effects of Ionizing Radiation, Vol. I, Scientific Annex A: Epidemiological studies of radiation and cancer. Publication E.08.IX.6, United Nations, New York, 2008.

15. R. R. Monson, Observations on the healthy worker effect. $J$. Occup. Med. 28, 425-433 (1986).

16. G. R. Howe, A. M. Chiarelli and J. P. Lindsay, Components and modifiers of the healthy worker effect: evidence from three occupational cohorts and implications for industrial compensation. Am. J. Epidemiol. 128, 1364-1375 (1988).

17. H. Checkoway, N. Pearce and D. J. Crawford-Brown, Research Methods in Occupational Epidemiology. Oxford University Press, New York, 1989.

18. A. J. Fox and P. F. Collier, Low mortality rates in industrial cohort studies due to selection for work and survival in the industry. Br. J. Prev. Soc. Med. 30, 225-230 (1976).

19. H. O. Adami, D. Hunter and D. Trichopoulos, Textbook of Cancer Epidemiology, 2nd ed. Oxford University Press, New York, 2008.

20. International Agency for Research on Cancer (IARC), IARC Monographs on the Evaluation of Carcinogenic Risks to Humans, Vol. 78, Ionizing Radiation, Part 2: Some Internally Deposited Radionuclides. IARC, Lyon, France, 2001.

21. National Research Council (NRC), Review of toxicologic and radiologic risks to military personnel from exposure to depleted uranium during and after combat. The National Academies Press, Washington DC, 2008.

22. Royal Society Working Group on the Health Hazards of Depleted Uranium Munitions. The Health Hazards of Depleted Uranium Munitions, Part 1. The Royal Society, London, 2001.

23. Institute of Medicine (IOM), Committee on Gulf War and Health: Updated Literature Review of Depleted Uranium. Gulf War and Health: Updated Literature Review of Depleted Uranium. National Academies Press, Washington DC, 2008.
24. I. G. Canu, S. Jacob, E. Cardis, P. Wild, S. Caër-Lorho, B. Auriol, D. Laurier and M. Tirmarche, Reprocessed uranium exposure and lung cancer risk. Health Phys. 99, 308-313 (2010).

25. L. E. Pinkerton, T. F. Bloom, M. J. Hein and E. M. Ward, Mortality among a cohort of uranium mill workers: an update. Occup. Environ. Med. 61, 57-64 (2004).

26. J. D. Boice Jr., S. S. Cohen, M. T. Mumma, B. Chadda and W. J. Blot, A cohort study of uranium millers and miners of Grants, New Mexico, 1979-2005. J. Radiol. Prot. 28, 303-325 (2008).

27. E. A. Dupree, J. P. Watkins, J. N. Ingle, P. W. Wallace, C. M. West and W. G. Tankersley, Uranium dust exposure and lung cancer risk in four uranium processing operations. Epidemiology 6, 370-375 (1995).

28. R. W. Leggett, The behavior and chemical toxicity of $\mathrm{U}$ in the kidney: a reassessment. Health Phys. 57, 365-383 (1989).

29. R. L. Kathren and R. K. Burklin, Acute chemical toxicity of uranium. Health Phys. 94, 170-179 (2008).

30. Institute of Medicine (IOM), Committee on the Health Effects Associated with Exposures During the Gulf War, Gulf War and Health, Vol. 1, Depleted Uranium, Pyridostigmine Bromide, Sarin, Vaccines. National Academies Press, Washington DC, 2000.

31. R. L. Kathren and R. H. Moore, Acute accidental inhalation of U: a 38-year follow-up. Health Phys. 51, 609-619 (1986).

32. M. A. McDiarmid, S. M. Engelhardt, M. Oliver, P. Gucer, P. D. Wilson, R. Kane, A. Cernich, B. Kaup, L. Anderson and K. S. Squibb, Health surveillance of Gulf War I veterans exposed to depleted uranium: updating the cohort. Health Phys. 93, 60-73 (2007).

33. E. Cardis, M. Vrijheid, M. Blettner, E. Gilbert, M. Hakama, C. Hill, G. Howe, J. Kaldor, C. R. Muirhead and K. Veress, Risk of cancer after low doses of ionizing radiation: retrospective cohort study in 15 countries. Radiat. Res. 167, 396-416 (2007).

34. C. R. Muirhead, J. A. O'Hagan, R. G. Haylock, M. A. Phillipson, T. Willcock, G. L. Berridge and W. Zhang, Mortality and cancer incidence following occupational radiation exposure: third analysis of the National Registry for Radiation Workers. Br. J. Cancer 100, 206-212 (2009).

35. J. D. Boice Jr., Uncertainties in studies of low statistical power. $J$. Radiol. Prot. 30,115-120 (2010).

36. E. S. Gilbert, The impact of dosimetry uncertainties on doseresponse analyses. Health Phys. 97, 487-492 (2009).

37. J. D. Boice Jr., Lauriston S. Taylor Lecture: Radiation epidemiology - The golden age and future challenges. Health Phys. 100, 59-76 (2011). 